\title{
Impact of Allium sativum ethanol extract on immuno-regulatory $T$ cells and anti-inflammatory cytokine profile in murine schistosomiasis
}

\author{
Hamad, R.S. ${ }^{1,2^{*}}$, Abd El-Moaty, H.I. ${ }^{1,3}$ \\ ${ }^{1}$ Biological Sciences Department, Faculty of Science, King Faisal University, Al-Ahsa, Saudi Arabia \\ ${ }^{2}$ Central Laboratory, Theodor Bilharz Research Institute, Giza, Egypt \\ ${ }^{3}$ Medicinal and Aromatic Plants Department, Desert Research Center El-Mataria, Cairo 11753, Egypt. \\ *Corresponding author: rhamad@kfu.edu.sa
}

\section{ARTICLE HISTORY}

Received: 10 April 2021

Revised: 1 September 2021

Accepted: 1 September 2021

Published: 21 December 2021

\begin{abstract}
Parasite immune response against schistosomal antigens involves both the innate and adaptive immune response. Tregs have a suppressive effect and play a role on the parasite's immune evasion. This study aimed to evaluate active compounds of Allium sativum (AS) ethanol extract and the impact of $A S$ extract alone or in combination with praziquantel on Tregs and anti-inflammatory cytokines TGF- $\beta$ and IL-10 in mice infected with $S$. mansoni. Phytochemical screening of AS bulbs for various active constituents and qualitative and quantitative analysis of the flavonoids and phenolic acids were done using HPLC. Measurement of splenocytes Treg cell phenotypes and anti-inflammatory cytokines TGF- $\beta$ and IL-10 was done by flow cytometric analysis. The data are expressed as mean \pm SD. Statistical significance was determined by one-way ANOVA utilizing the statistical package (SPSS version 17.0). HPLC of AS ethanol extract revealed presence of 22 and 18 compounds of flavonoids and phenolic acids, respectively. S. mansoni infection upregulated the Treg cells subsets (CD4, CD25, Foxp3) frequencies and the levels of TGF- $\beta$ and IL-10 anti-inflammatory cytokines when compared to healthy control. AS ethanol extract alone or combined with PZQ decreases the production of Treg cells from spleen in addition to the reduction in antiinflammatory cytokines IL-10 and TGF- $\beta$. This study recommends that the combination of AS ethanol extract and PZQ may play a role in maintaining the homeostasis of the immune system during schistosomiasis by decreasing Treg cells and anti-inflammatory cytokines IL10 and TGF- $\beta$ production.
\end{abstract}

Keywords: Schistosoma mansoni; Allium sativum; Tregs; TGF- $\beta$; IL-10.

\section{INTRODUCTION}

Schistosomiasis, is a neglected tropical disease causing a public health problem in tropical and subtropical regions (Colley et al., 2014). It infects nearly 300 million people in about 78 countries, primarily in Africa (Cioli et al., 2014; Aula et al., 2021). The parasite immune response against schistosomal antigens involves both the innate and adaptive immune response. In acute $S$. mansoni infection, antigen presenting cells (APC) such as macrophages and dendritic cells introduce the schistosome antigens on major histocompatibility complex-II (MHC-II) to T helper lymphocytes leading to the proliferation of Th1 responses through the production of proinflammatory cytokines including Tumor necrosis factor- $\alpha$ (TNF- $\alpha$ ), Interleukin (IL)-1, IL-12 and interferon gamma (IFN- $\gamma$ ) in addition to the chemokine IL-8 (Pearce \& MacDonald, 2002; El Ridi et al., 2006). In the chronic phase of infection, this immune response is shifted, toward the much stronger Th2 response, reflecting a state of immune suppression triggered by regulatory $T$ cells (Treg) and a production of IL-10 and transforming growth factor- $\beta$ (TGF- $\beta$ ) (Taylor et al., 2006; Maizels \& Smith, 2011; Taylor et al., 2012). Treg cells is reported to play an important down-regulatory role in limiting protective immunity during chronic schistosome infections (Watanabe et al., 2007; Tang et al., 2011; Schmiedel et al., 2015).

The schistosomiasis control is based principally on treatment with anthelmintic drug namely praziquantel (PZQ) (Doenhoff et al., 2008; Cioli et al., 2014). Many reports indicated a resistance to $P Z Q$, through the induction of immune response by increasing IgE levels, decreasing IgG4 levels and production of IL-4, IL-5, IL-10, and IL-13 and IFN- $\gamma$ responses (Black et al., 2010; Ricciardi et al., 2018); these responses lead to increase resistance to re-infection (Black et al., 2010). Consequently, there is a strong need for discovering alternatives to that available drug. For this reason, extracts of natural products from medicinal plants were potentially used for controlling the disease. 
Allium sativum (AS) L. (family: Amaryllidaceae) is an aromatic herbaceous annual aroma spice and commonly known as garlic. It is commonly used as a food ingredient due to its distinctive taste and possible health benefits in many countries and different cultures, consumption of garlic is used to promote health and well-being, in addition to liver diseases. Numerous studies indicated the role of garlic consumption in reduction of developing chronic diseases such as: cardiovascular disease, cancer, obesity, diabetes, high blood pressure, platelet aggregation and cholesterol reduction (Hussain et al., 1990; Lawson et al., 1992; Virginia, 2006). Additionally, garlic and its derivatives showed strong antioxidant, anti-inflammatory, and immunoregulatory properties (Arreola et al., 2015; Aly et al., 2017; Batiha et al., 2020). These health properties of garlic are derived from its polyphenols and organosulfur compounds (Lawson \& Gardner, 2005; Shang et al., 2019). AS was successfully used against parasites such as E. granulosus, Trypanosoma brucei, Schistosoma mansoni and Leishmania tarentolae (Aly et al., 2017; Krstin et al., 2018; Mohammadi et al., 2018; Shirgholami et al., 2021).

To the best of our knowledge, there has been no study on the impact of $A S$ extract administration on regulatory $T$ cells immune response in the $S$. mansoni infected mice. The present work aimed to evaluate the active compounds of $A S$ ethanol extract and its impact on the regulatory $T$ cells and anti-inflammatory cytokines TGF- $\beta$ and IL-10 in the S. mansoni infected mice, in comparison with the standard drug PZQ for treatment of schistosomiasis.

\section{MATERIALS AND METHODS}

\section{Parasites and animals}

Fifty male albino CD-1 mice weighing approximately 25 grams and age of 6 weeks, were obtained from Schistosome Biological Supply Program at Theodore Bilharz Research Institute (SBSP/TBRI), Giza, Egypt. Mice were maintained under a controlled condition and given access to water and standard commercial pellet diet. The animal experiments were carried out according to the animal ethics guidelines, after approval of the institutional ethical committee of TBRI.

\section{Mice infection}

Egyptian strain of S. mansoni cercariae were purchased from SBSP/TBRI, and used directly after shedding from Biomphalaria alexandrina snails. CD1 mice were infected by subcutaneous (SC) injection of $100 \pm 2$ S. mansoni cercariae/mouse (Peters \& Warren, 1969).

\section{Plant material}

Allium sativum (AS) was collected from a private farm, ElMansoura, Egypt, in the summer of 2019. The identification of the fresh plant was scientifically carried out in the herbarium of the Agricultural Museum, Giza (CAIM).

\section{Preparation of powdered air-dried bulbs of $A S$}

Fresh bulbs of $A S$ were separated, cleaned, dried in shade then in oven at approximately $50^{\circ} \mathrm{C}$ until the weight became constant. Dried bulbs then grounded to fine powder and prepared to be used in further investigations.

\section{AS bulbs extract preparation}

Five hundred grams of the bulbs of $A S$ was extracted with aqueous ethanol extract (70\%) using the soxhlet apparatus at $80^{\circ} \mathrm{C}$, and then filtration and evaporation of the alcoholic extract was done under reduced pressure till dryness and the dried extract was kept at room temperature for analysis.

\section{Phytochemical screening}

The initial phytochemical screening of AS bulbs for various active constituents in $70 \%$ ethanol extract was done according to Lala (1993). Assessment of alkaloids presence was done using the Dragendorff test (Ezeonu \& Ejikeme, 2016), while Molisch and Biuret tests were used for the determination of carbohydrates and proteins, respectively (Annapandian \& Rajagopal, 2017). Cardiac glycosides were determined using concentrated $\mathrm{H}_{2} \mathrm{SO}_{4}$ test (Obianime \& Uche, 2008), coumarin and flavonoids were determined by alcoholic sodium hydroxide and Pew's test, respectively. Saponin determined by the foam test, tannins were determined by ferric chloride test and Salkowski's test was used to determine terpenes (Ezeonu \& Ejikeme, 2016). The oil distillation method was used to assess volatile oils.

\section{Investigation of phenolic compounds using HPLC}

The bulbs of AS were analyzed using HPLC. HP 1090M Series high performance liquid chromatography with an HP 1090M Series diode array and an eight-channel electrochemical coulometric array detector (EC; Esa Inc., USA) was used. 100$800 \mathrm{mV}$ potentials were used to run the EC (100mV intervals). The detector array was placed at $35^{\circ} \mathrm{C}$ in a temperaturecontrolled compartment. The flavonoid and phenolic acids were separated using an ODS-3 $(4.0150 \mathrm{~nm}, 3 \mathrm{~m})$ column with a C-18 guard column at $35^{\circ} \mathrm{C}$. The mobile phase flow rate was $0.7 \mathrm{~mL} / \mathrm{min}$, and the injection volumes of the standards and sample extracts were $10 \mathrm{~L}$. The external standard procedure was used to measure both flavonoids and phenolic acids. Peak area (DAD) or beak height is used to quantify the animals (EC) s shown by Mattila et al. (2000).

\section{Praziquantel (PZQ)}

Purchased from SEDICO pharmaceutical Co. Giza, Egypt, in the form of tablets, each tablet contains $600 \mathrm{mg} / \mathrm{kg}$. Tablets were crushed into powder and suspended in $4.8 \mathrm{ml}$ distilled water according to the method of Muchirah et al. (2012). The freshly prepared drug was administered orally to the mice by stainless steel cannula.

\section{Drugs and Doses}

The dose of AS ethanol extract used were about $50 \mathrm{mg} / \mathrm{kg}$ of body weight (Riad et al., 2009). This dose was administered orally single dose per day for 40 days.

The dose of Praziquantel used were $500 \mathrm{mg}$ (dissolved in $70 \%$ glycerin) $/ \mathrm{kg}$ of body weight, and was administered orally 7 weeks post infection for two successive days (Panic et al., 2017).

\section{Experimental groups}

Mice were divided into five groups, with 10 mice each.

Group I: left uninfected and un-injected, represent the naïve group.

Group II: infected with $100 \pm 2$ S. mansoni cercariae/mouse; act as infected control group.

Group III: Mice were infected by S. mansoni cercariae/mouse and treated with AS aqueous ethanol extract;

Group IV: Mice were infected by S. mansoni cercariae/mouse and treated with PZQ.

Group V: Mice were infected by S. mansoni cercariae/mouse and received mixed treatment of PZQ and $A S$ ethanol extract at the same doses and timeline as in group III and IV. 
Mice were sacrificed eight weeks after infection with $100 \pm 2$ S. mansoni cercariae/mouse and the following testes were carried out.

\section{Flow cytometric (FCM) analysis}

\section{Spleen cells isolation}

Spleens from at least five mice per group were isolated and forced through $70 \mu \mathrm{m}$ cell strainer (BD Biosciences, San Jose, CA, USA) to obtain a single-cell suspension to analyze cell surface molecules and regulatory $T$ cells using flow cytometry. Splenic red blood cells (RBCs) were lysed by RBCs lysis buffer (Sigma) and remaining splenic cells were washed twice by a pyrogenic saline. Trypan blue dye was used to evaluate the cell viability.

\section{Flow cytometry}

For the measurement of regulatory T-cell phenotypes, the splenocytes single-cell suspension from each mouse was adjusted to $1 \times 10^{6}$ cells/well, incubated with the following monoclonal antibodies (mAbs) for surface marker analysis using mouse regulatory $T$ cell staining kit (BioLegend Inc, San Diego, CA) according to the manufacturer's protocol:

-fluorescein isothiocyanate (FITC) -conjugated anti-CD4 mAbs, FITC -conjugated anti- CD25 mAbs, phycoerythrin (PE)- antimouse FOXP3 Antibody, FITC anti-mouse IL-10 Antibody and FITC anti-mouse LAP (TGF- $\beta 1$ ) Antibody. Blocking of the nonspecific binding was done using $4 \mu \mathrm{g}$ rat $\lg \mathrm{G}$ per $1 \times 10^{6}$ cells.

The flow cytometric analysis was performed using BD Accuri C6 Flow Cytometer (BD Biosciences). Data were analyzed using $\mathrm{C} 6$ Analysis software (BD Biosciences).

\section{Statistical analyses}

Data were first tested for normality using the KolmogorovSmirnov test, and after ensuring the normality of the data, one-way ANOVA was used to determine the statistical significance by utilizing the statistical package (SPSS version 17.0). Data are expressed as mean \pm standard deviation of the mean (SD). $\mathrm{P}<0.05$ was considered as significant for all statistical analyses.

\section{RESULTS}

\section{Phytochemical screening}

The initial phytochemical screening of AS bulbs aqueous ethanol extract (70\%) indicated the existence of flavonoids, carbohydrates, glycosides, tannins, coumarins, alkaloids, terpenoids, saponins and essential oils.

\section{Investigation of phenolic compounds using HPLC}

HPLC of AS bulb aqueous ethanol extract (70\%) revealed the presence of 22 and 18 compounds of flavonoids and phenolic acids, respectively. Where the major flavonoid compounds were Rutin $(34.156 \mathrm{mg} / 100 \mathrm{~g})$, Hespiridin $(31.211 \mathrm{mg} / 100 \mathrm{~g})$, Luteolin-6- arbinose-8- glucose $(30.254 \mathrm{mg} / 100 \mathrm{~g})$, Quercetin $(29.604 \mathrm{mg} / 100 \mathrm{~g})$ and Naringenin $(27.954 \mathrm{mg} / 100 \mathrm{~g})$, while the major phenolic acid compounds were Ferulic acid (37.326 $\mathrm{mg} / 100 \mathrm{~g})$, p-Coumaric acid $(32.634 \mathrm{mg} / 100 \mathrm{~g})$ and Chlorogenic acid (32.634 mg/100g) (Table 1).

Effects of $S$. mansoni infection on host Regulatory $T$ cell subsets (CD4, CD25, Foxp3) and anti-inflammatory cytokine profile

In each of two independent experiments, CD1 mice were infected with $100 \pm 2$ S. mansoni cercariae/mouse. The percentage of spleen Treg cell subsets (CD4, CD25, Foxp3) and the anti-inflammatory cytokine responses, were compared to uninfected mice. Flow cytometric analysis showed that, infection with $S$. mansoni led to significant $(p<0.001)$ increase in spleen Treg cell subsets (CD4, CD25, Foxp3) (Figure 1-3). These changes were associated with significant $(p<0.001)$ increase in IL-10 and TGF- $\beta$ anti-inflammatory cytokines (Figure 4, 5).

Table 1. HPLC analysis of aqueous ethanol extracts (70\%) of AS bulbs

\begin{tabular}{|c|c|c|c|c|}
\hline No & Flavonoids & $\mathrm{Mg} / 100 \mathrm{~g}$ & Phenolic acids & $\mathrm{Mg} / 100 \mathrm{~g}$ \\
\hline 1 & Luteolin-6- arbinose-8- glucose & 30.254 & Pyrogallol acid & 13.210 \\
\hline 2 & Luteolin-6- glucose -8- arbinose & 1.154 & Gallic acid & 20.352 \\
\hline 3 & Apigenin-6- arbinose -8-glactose & 24.029 & 4-Amino-benzoic acid & 2.120 \\
\hline 4 & Apignin-6- rhamnose -8- glucose & 0.523 & Catechein acid & 3.254 \\
\hline 5 & Apignin-6- glucose -8- rhamnose & 20.083 & Catechol acid & 14.015 \\
\hline 6 & Luteolin-7-glucose & 4.189 & Epicatachin acid & 0.823 \\
\hline 7 & Narengin & 0.764 & p-OH-benzoic acid & 0.531 \\
\hline 8 & Rutin & 34.156 & Chlorogenic acid & 28.687 \\
\hline 9 & Hespiridin & 30.537 & Vanillic acid & 0.231 \\
\hline 10 & Quercetin-3-O-glucoside & 0.660 & Caffeic acid & 1.425 \\
\hline 11 & Rosmarinic & 0.758 & p-Coumaric acid & 32.634 \\
\hline 12 & Apigenin-7-0- neohespiroside & 0.298 & Ferulic acid & 37.326 \\
\hline 13 & Kampferol-3,7-dirhamoside & 2.432 & Iso-ferulic acid & 2.919 \\
\hline 14 & apigenin-7-glucose & 4.302 & $\alpha$-coumaric acid & 10.446 \\
\hline 15 & Quercetrin & 0.263 & Benzoic acid & 23.211 \\
\hline 16 & Quercetin & 29.604 & Ellagic acid & 18.214 \\
\hline 17 & Naringenin & 27.954 & 3,4,5-methoxy-cinnamic acid & 3.125 \\
\hline 18 & Hespirtin & 25.811 & Salycilic acid & 0.238 \\
\hline 19 & Kampferol & 23.128 & - & - \\
\hline 20 & Rhamnetin & 0.468 & - & - \\
\hline 21 & Apignin & 10.360 & - & - \\
\hline 22 & Acacetin & 0.168 & - & - \\
\hline
\end{tabular}


[a]

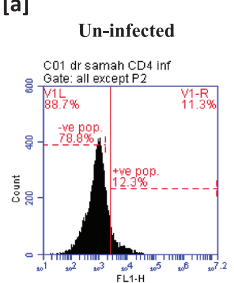

Infected



Infected + PZQ injected

Infected-AS+PZQ injected
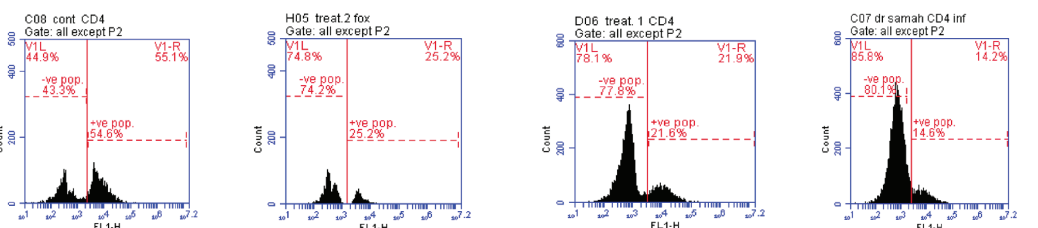

[b]

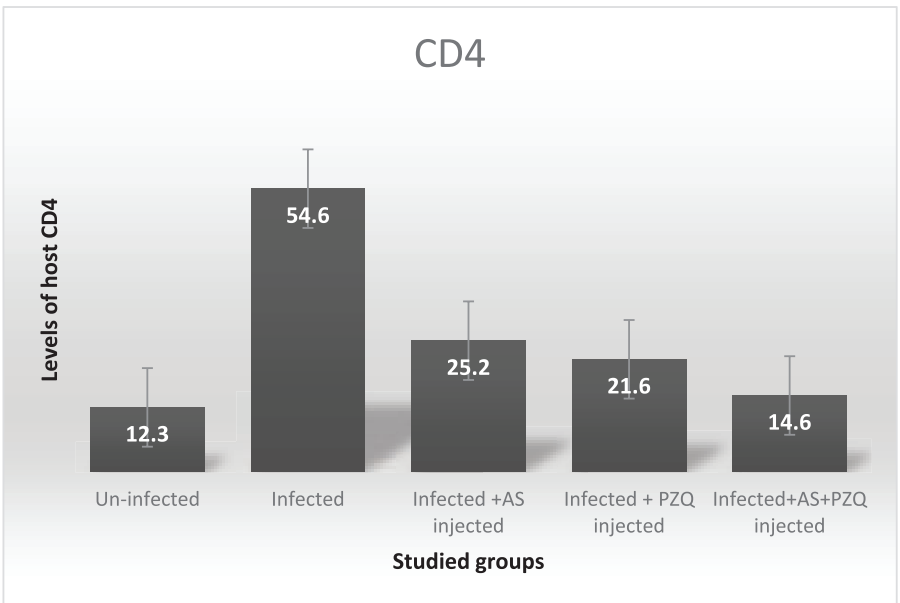

Figure 1. Effects of S. mansoni infection, AS ethanol extract and/or PZQ treatment on host splenic CD4 regulatory T cells. [A] Flow cytometric analysis of the spleen CD4 Treg cell subsets [B] The percentages numbers of CD4 Treg cell subsets. All data are measured by mean \pm SD and representative of two separate experiments five mice per group. $* P<0.05, * * P<0.01, * * * P<0.001$. AS: Allium sativum; PZQ: Praziquantel.

[a]
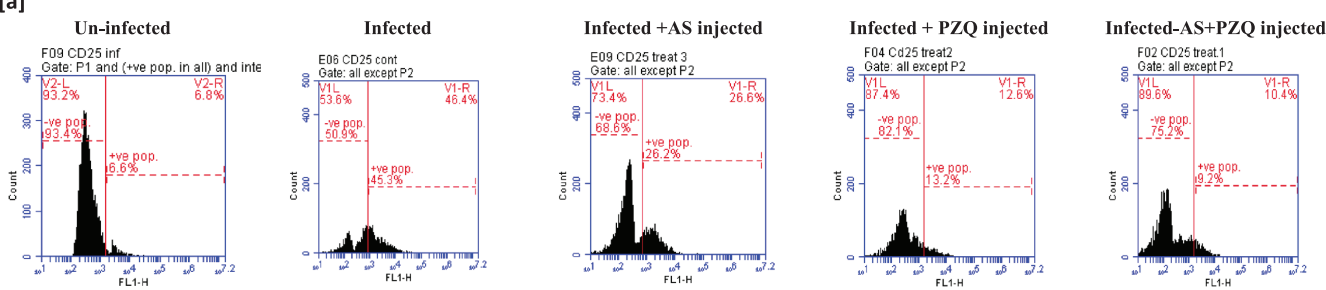

[b]

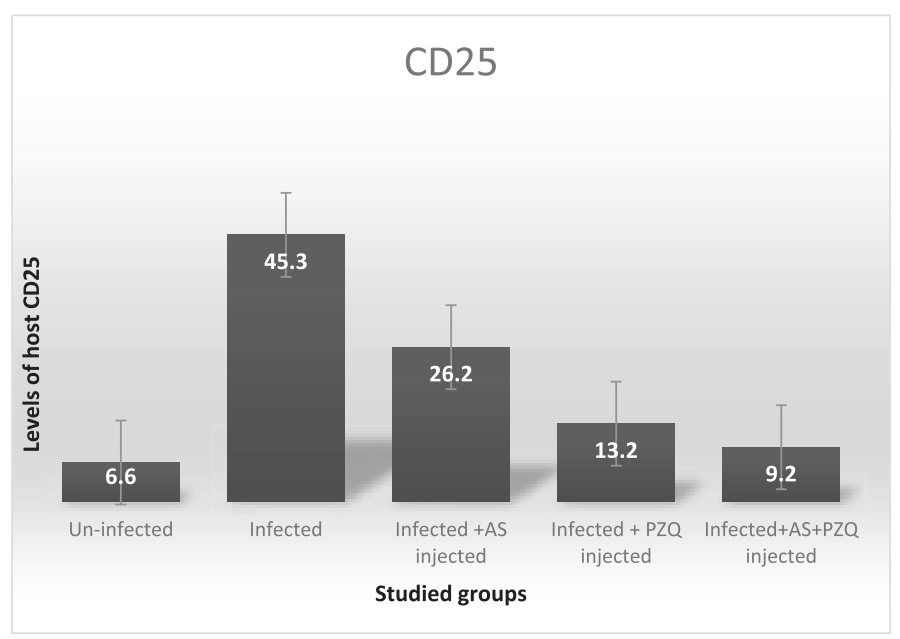

Figure 2. Effects of $S$. mansoni infection, AS ethanol extract and/or PZQ treatment on host splenic CD25 regulatory T cells. [A] Flow cytometric analysis of the spleen CD25 Treg cell subsets [B] The percentages numbers of CD25 Treg cell subsets. All data are measured by mean \pm SD and representative of two separate experiments five mice per group. ${ }^{*} P<0.05, * * P<0.01, * * * P<0.001$. AS: Allium sativum; PZQ: Praziquantel. 

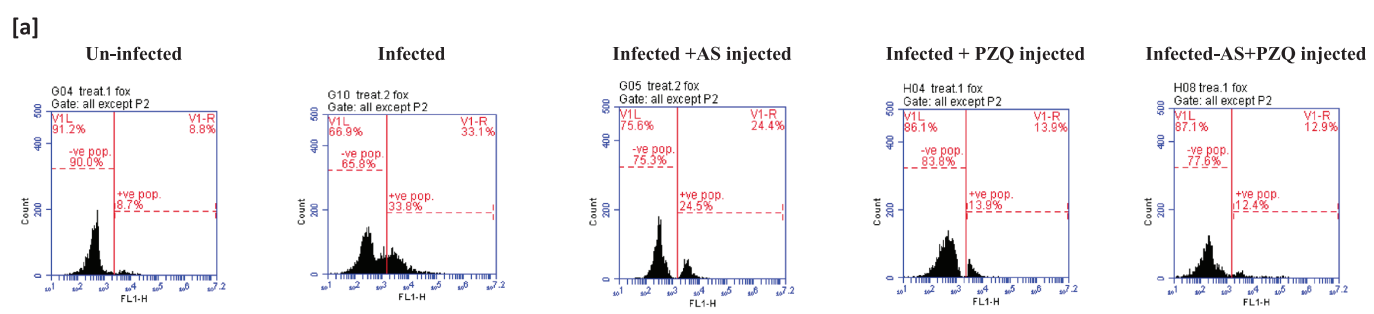

[b]

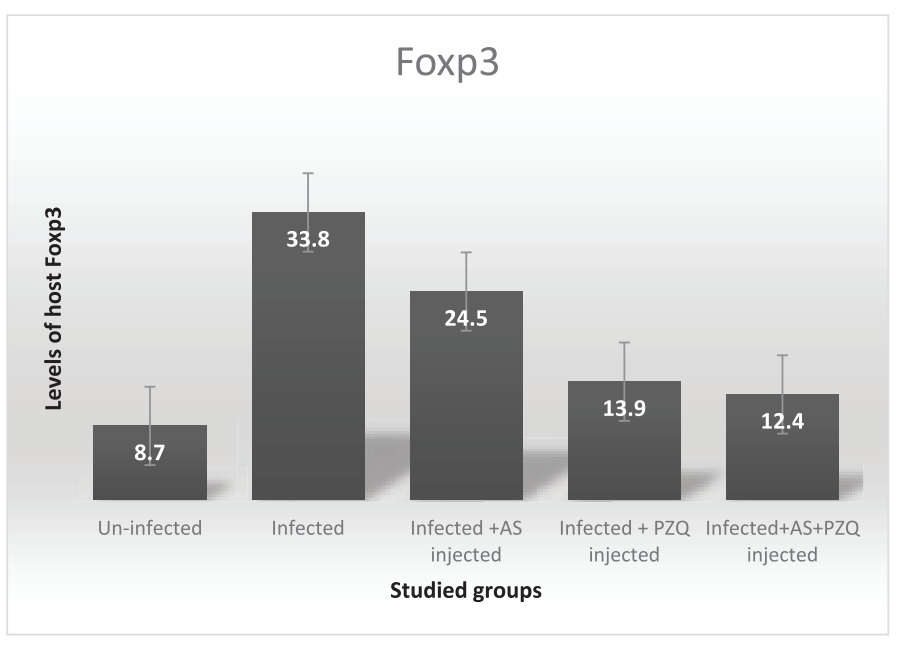

Figure 3. Effects of S. mansoni infection, AS ethanol extract and/or PZQ treatment on host splenic Foxp3 regulatory $\mathrm{T}$ cells. [A] Flow cytometric analysis of the spleen Foxp3 Treg cell subsets [B] The percentages numbers of Foxp3 Treg cell subsets. All data are measured by mean \pm SD and representative of two separate experiments five mice per group. ${ }^{*} P<0.05, * * P<0.01, * * * P<0.001$. AS: Allium sativum; PZQ: Praziquantel.
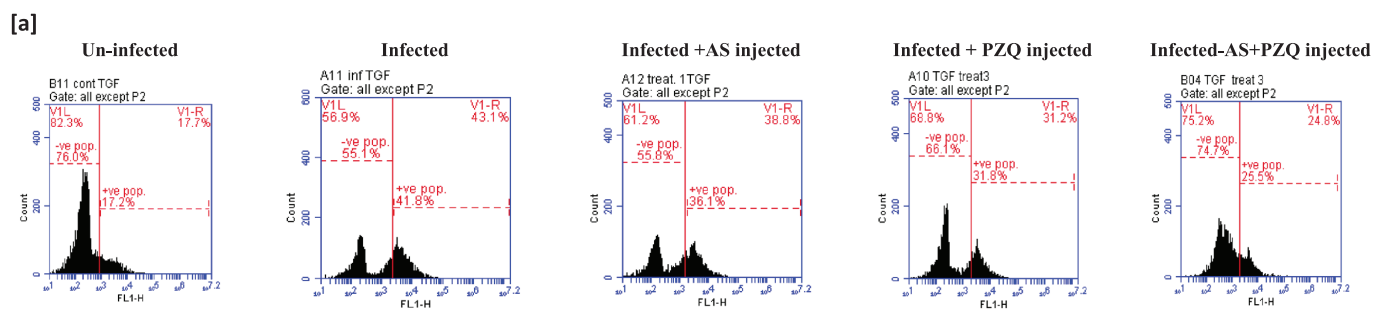

[b]

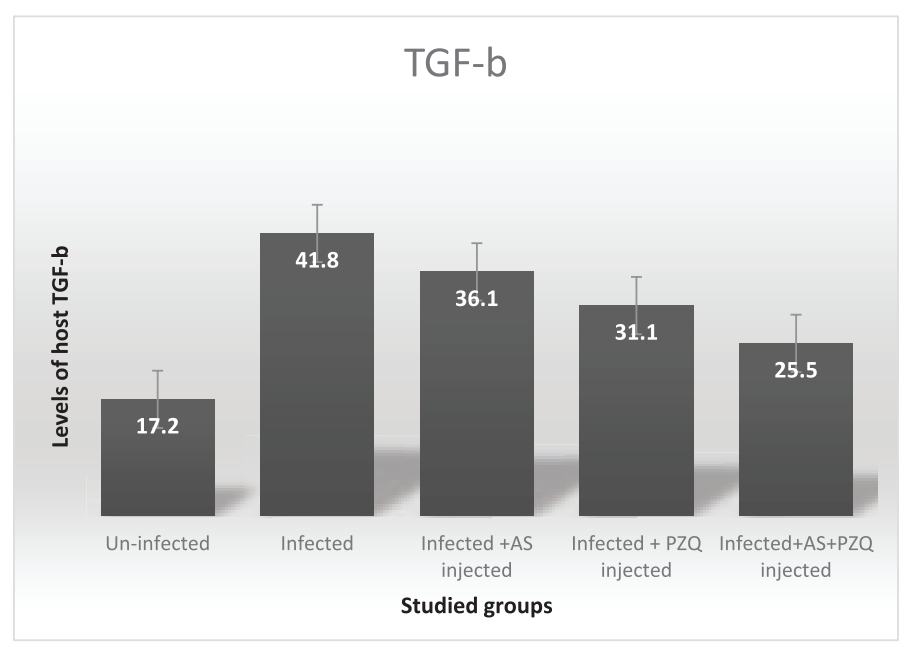

Figure 4. Effects of S. mansoni infection, AS ethanol extract and/or PZQ treatment on host TGF-b cytokine. [A] Flow cytometric analysis of the TGF-b cytokine. [B] The percentages numbers of TGF-b cytokine. All data are measured by mean \pm SD and representative of two separate experiments five mice per group. ${ }^{*} P<0.05,{ }^{*} p<0.01, * * * P<0.001$. AS: Allium sativum; PZQ: Praziquantel. 
[a]
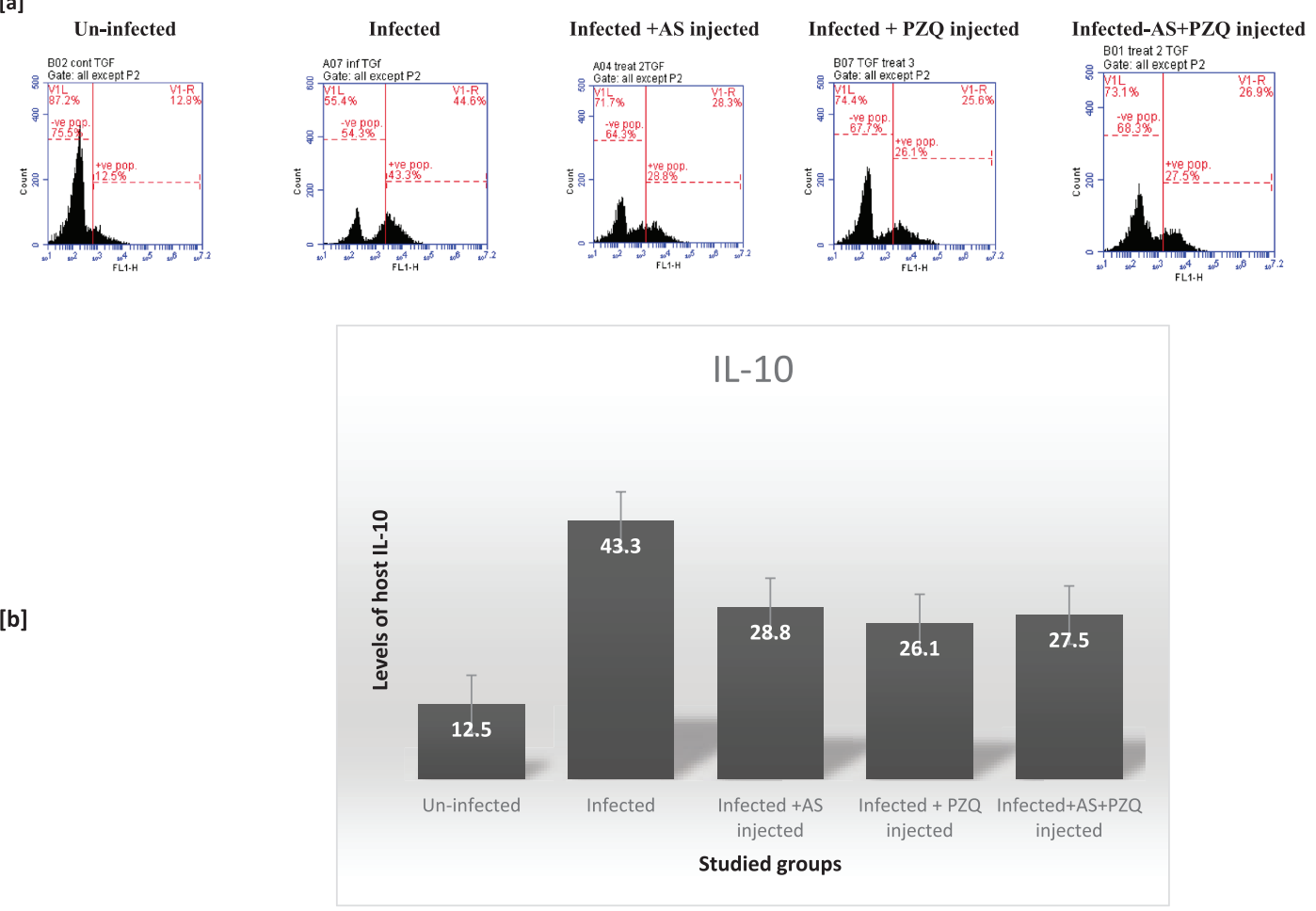

Figure 5. Effects of S. mansoni infection, AS ethanol extract and/or PZQ treatment on host IL-10 cytokine. [A] Flow cytometric analysis of the TGF-b cytokine. [B] The percentages numbers of IL-10 cytokine. All data are measured by mean \pm SD and representative of two separate experiments five mice per group. ${ }^{*} P<0.05,{ }^{*} P<0.01, * * * P<0.001$. AS: Allium sativum; PZQ: Praziquantel.

Effects of treatment with AS ethanol extract, PZQ individually or in combination with AS ethanol extract on host Regulatory $T$ cell subsets (CD4, CD25, Foxp3) and anti-inflammatory cytokine profile In each of two independent experiments, treatment of S. mansoni infected CD1 mice with AS ethanol extract PZQ individually or in combination with AS ethanol extract elicited significant decrease $(p<0.01 ; p<0.001 ; p<0.001)$ respectively, in spleen Treg cell subsets (CD4, CD25, Foxp3), as compared to infected controls (Figure 1-3). These changes were associated with significant $(p<0.05)$ decrease in IL-10 and TGF- $\beta$ anti-inflammatory cytokines (Figure 4,5 ).

\section{DISCUSSION}

Tregs have a suppressive effect, and are involved in immune tolerance and induction, in addition to their central role on the parasite's immune evasion. Foxp3 is a nuclear transcription factor and is a characteristic marker of Tregs and the expression of Foxp3 determines their suppressive role (lizuka-Koga et al., 2017). Treg cells secrete suppressive cytokines such as TGF- $\beta$ and IL-10, therefore, the function of Treg cells is closely related with the effect of its secreted cytokines. Tang et al. (2011) reported that Tregs contributed to the escape of $S$. japonicum from the host immune responses. Consequently, Treg cells and its anti-inflammatory cytokines, TGF- $\beta$ and IL-10, can be used as indicators to study immune response associated with schistosomiasis. AS is considered as a capable candidate for maintaining the homeostasis of the immune system. Thus, different studies have demonstrated interesting beneficial effects of garlic on the immunity and immune cells.
The present work aimed to evaluate the active compounds of $A S$ ethanol extract and its impact on the regulatory T cells and anti-inflammatory cytokines TGF- $\beta$ and IL-10 in the $S$. mansoni infected mice, in comparison with the standard drug PZQ for treatment of schistosomiasis.

The present study indicates that AS bulb extracts which is grown in Egypt contain several bioactive constituents (flavonoids, carbohydrates, glycosides, tannins, coumarins, alkaloids, terpenoids, saponins and essential oils) and showed similar results to the Phan et al. (2019). On the other hand, the AS bulb extracts contains the major compounds of the flavonoid glycosides (rutin, hespiridin and luteolin-6arbinose-8- glucose), aglycone (quercetin and naringenin) and phenolic acids (Ferulic acid, p-Coumaric and Chlorogenic acid). In the present study, the major phenolic compounds found in garlic grown in Egypt differed marginally from the polyphenolics of nine commercial garlic varieties grown in different countries (Szychowski et al., 2018).

Our results showed that $S$. mansoni infection led to the upregulation of the Treg cells subsets (CD4, CD25, Foxp3) frequencies and the levels of both TGF- $\beta$ and IL-10 antiinflammatory cytokines when compared to healthy control. These results are in consistent with previous reports indicating increased in frequencies of Treg cells and the levels of TGF- $\beta$ and IL-10 in parallel in schistosome-infected mice (Tang et al., 2011; Turner et al., 2011; Schmiedel et al., 2015; He et al., 2018). These data also go along with those found that the chronic phase of schistosome infection led to shifted immune response from Th1 toward Th2 response, causing a state of immune suppression through elevation of Treg cells and the production of IL-10 and TGF- $\beta$ (Taylor et al., 2006; Maizels \& Smith, 2011; Taylor et al., 2012). 
Oral administration of $S$. mansoni infected CD1 mice with AS ethanol extract or PZQ individually elicited significant decrease, in spleen Treg cell subsets (CD4, CD25, Foxp3), as compared to infected controls. These changes were associated with significant $(p<0.05)$ decrease in IL-10 and TGF- $\beta$ anti-inflammatory cytokines. Our observation of reduced immunosuppressive cells suggests that $A S$ ethanol extract can maintain the homeostasis of immune functions. On the other hand, the combination treatment of $A S$ ethanol extract with PZQ showed improved activity against the significant increase in spleen Treg cell subsets (CD4, CD25, Foxp3), as compared to infected controls, and IL-10 and TGF- $\beta$ anti-inflammatory cytokines.

\section{CONCLUSION}

This study showed that AS ethanol extract decreases the production of Treg cells from spleen in addition to the reduction in anti-inflammatory cytokines IL-10 and TGF- $\beta$. Therefore, AS ethanol extract may be a suitable alternative herbal treatment for the prevention of schistosomiasis. However, this study recommends that the combination of AS ethanol extract and PZQ may play a role in maintaining the homeostasis of the immune system during schistosomiasis by decreasing Treg cells and anti-inflammatory cytokines IL-10 and TGF- $\beta$ production. It is not yet fully understood the mechanism of how AS extract can cause reduction in Treg cells. However, it is notable that there are active compounds in AS bulb that may deactivate Treg cells proliferation and provide a protective pattern. Therefore, a further study on the impact of the AS active compounds on the Treg cells during schistosomiasis is highly recommended.

\section{ACKNOWLEDGEMENTS}

The authors acknowledge the Deanship of Scientific Research at King Faisal University for the financial support under Nasher Track (Grant No. 216065). We would like to thank Dr. S.I. Ghoname and M.S. Gouida for assisting flow cytometry analysis. Thank you to colleagues from TBRI.

\section{Conflict of Interests}

Authors declare that there is no Conflict of Interests.

\section{REFERENCES}

Aly, I., Taher, E.E., Hoda, E.S., Mohammed, F.A., ELnain, G., Hamad, R.S. \& Bayoumy, E.M. (2017). Efficacy of soluble glycoprotein fraction from Allium sativum purified by size exclusion chromatography on murine Schistosomiasis mansoni. Microbial Pathogenesis 107: 243-248. https:// doi.org/10.1016/j.micpath.2017.03.039.

Annapandian, V.M. \& Rajagopal, S.S. (2017). Phytochemical evaluation and in vitro antioxidant activity of various solvent extracts of Leucas aspera (Willd.) Link leaves. Free Radicals and Antioxidants 7: 166-171. https://doi.org/10.5530/ fra.2017.2.25

Arreola, R., Quintero-Fabián, S., López-Roa, R.I., FloresGutiérrez, E.O., Reyes-Grajeda, J.P., Carrera-Quintanar, L. \& Ortuño-Sahagún, D. (2015). Immunomodulation and anti-inflammatory effects of garlic compounds. Journal of Immunology Research 2015: 401630. https://doi.org/10.1155/ 2015/401630

Aula, O.P., McManus, D.P., Jones, M.K. \& Gordon, C.A. (2021). Schistosomiasis with a focus on Africa. Tropical Medicine and Infectious Disease 6: 109. https://doi.org/10.3390/ tropicalmed6030109
Batiha, G.E., Magdy Beshbishy, A., Wasef, L.G., Elewa, Y.H.A., Al-Sagan, A.A., El-Hack, M.E.A., Taha, A.E., Elhakim, Y.M.A. \& Prasad Devkota, H. (2020). Chemical constituents and pharmacological activities of garlic (Allium sativum L.): A review. Nutrients 12: 872. https://doi.org/10.3390/nu 12030872

Black, C.L., Mwinzi, P.N., Muok, E.M., Abudho, B., Fitzsimmons, C.M., Dunne, D.W., Karanja, D.M.S., Secor, W.E. \& Colley, D.G. (2010). Influence of exposure history on the immunology and development of resistance to human Schistosomiasis mansoni. PLoS neglected tropical diseases 4: e637. https://doi.org/10.1371/journal.pntd.0000637

Cioli, D., Pica-Mattoccia, L., Basso, A. \& Guidi, A. (2014). Schistosomiasis control: praziquantel forever? Molecular and Biochemical Parasitology 195: 23-29. https://doi.org/ 10.1016/j.molbiopara.2014.06.002

Colley, D.G., Bustinduy, A.L., Secor, W.E. \& King, C.H. (2014). Human schistosomiasis. The Lancet 383: 2253-2264. https:/ /doi.org/10.1016/S0140-6736(13)61949-2

Doenhoff, M.J., Cioli, D. \& Utzinger, J. (2008). Praziquantel: mechanisms of action, resistance and new derivatives for schistosomiasis. Current Opinion in Infectious Diseases 21: 659-667. https://doi.org/10.1097/QCO.0b013e328318978f

El Ridi, R., Wagih, A., Salem, R., Mahana, N., El Demellawy, M. \& Tallima, H. (2006). Impact of interleukin-1 and interleukin-6 in murine primary schistosomiasis. International Immunopharmacology 6: 1100-1108. https://doi.org/ 10.1016/j.intimp.2006.01.021

Ezeonu, C.S. \& Ejikeme, C.M. (2016). Qualitative and quantitative determination of phytochemical contents of indigenous Nigerian softwoods. New Journal of Science 2016: 1-9. https://doi.org/10.1155/2016/5601327

He, L., Zhou, S., Qi, Q., Chi, Y., Zhu, J., Xu, Z., Wang, X., Hoellwarth, J., Liu, F., Chen, X. et al. (2018). The regulation of regulation: interleukin 10 increases $\mathrm{CD}^{+}{ }^{+} \mathrm{CD} 25^{+}$regulatory $\mathrm{T}$ cells but impairs their immunosuppressive activity in murine models with schistosomiasis japonica or asthma. Immunology 153: 84-96. https://doi.org/10.1111/imm.12813

Hussain, S.P., Jannu, L.N. \& Rao, A.R. (1990). Chemo preventive action of garlic on methylcholanthrene-induced carcinogenesis in the uterine cervix of mice. Cancer Letters 49: 175-180. https://doi.org/10.1016/0304-3835(90)90155-Q

lizuka-Koga, M., Nakatsukasa, H., Ito, M., Akanuma, T., Lu, Q. \& Yoshimura, A. (2017). Induction and maintenance of regulatory $T$ cells by transcription factors and epigenetic modifications. Journal of Autoimmunity 83: 113-121. https:/ /doi.org/10.1016/j.jaut.2017.07.002

Krstin, S., Sobeh, M., Braun, M.S. \& Wink, M. (2018). AntiParasitic Activities of Allium sativum and Allium cepa against Trypanosoma b. brucei and Leishmania tarentolae. Medicines 5: 37. https://doi.org/10.3390/medicines5020037

Lala, P.K. (1993). Lab manuals of Pharmacognosy. 5th edition. CSI Publishers and Distributors, Calcutta, pp. 38-48.

Lanzotti, V. (2006). The analysis of onion and garlic. Journal of chromatography A 1112: 3-22.p https://doi.org/10.1016/ j.chroma.2005.12.016

Lawson, L.D. \& Gardner, C.D. (2005). Composition, stability, and bioavailability of garlic products used in a clinical trial. Journal of Agricultural and Food Chemistry 53: 62546261.p https://doi.org/10.1021/jf050536

Lawson, L.D., Ransom, D.K. \& Hughes, B.G. (1992). Inhibition of whole blood platelet-aggregation by compounds in garlic clove extracts and commercial garlic products. Thrombosis Research 65: 141-156. https://doi.org/10.1016/ 0049-3848(92)90234-2 
Maizels, R.M. \& Smith, K.A. (2011). Regulatory T cells in infection. Advances in Immunology 112: 73-136. https:// doi.org/10.1016/B978-0-12-387827-4.00003-6

Mattila, P., Astola, J. \& Kumpulainen, J. (2000). Determination of flavonoids in plant material by HPLC with diode-array and electro-array detections. Journal of Agricultural and Food Chemistry 48: 5834-5841. https://doi.org/10.1021/jf000661f

Mohammadi, K.H., Heidarpour, M. \& Borji, H. (2018). In vivo therapeutic efficacy of the Allium sativum $\mathrm{ME}$ in experimentally Echinococcus granulosus infected mice. Comparative Immunology, Microbiology and Infectious Diseases 60: 23-27. https://doi.org/10.1016/j.cimid.2018. 10.001

Muchirah, P.N., Yole, D., Kutima, H., Waihenya, R., Kuria K.M. \& John, M. (2012). Determination of effective praziquantel dose in different mouse strains: BALB/c and Swiss mice in treatment of Schistosoma mansoni. Journal of Clinical Immunology and Immunopathology Research 4: 12-21. http:// doi.org/10.5897/JCIIR12.004

Obianime, A.W. \& Uche, F.I. (2008). The Phytochemical screening and the effects of methanolic extract of Phyllanthus amarus leaf on the biochemical parameters of male guinea pigs. Journal of Applied Sciences and Environmental Management 12: 73-77. https://doi.org/ 10.4314/jasem.v12i4.55222

Panic, G., Ruf, M.T. \& Keiser, J. (2017). Immunohistochemical investigations of treatment with Ro 13-3978, praziquantel, oxamniquine, and mefloquine in Schistosoma mansoniinfected mice. Antimicrobial Agents and Chemotherapy 61: e01142-17. https://doi.org/10.1128/AAC.01142-17

Pearce, E.J. \& MacDonald, A.S. (2002). The immunobiology of schistosomiasis. Nature Reviews Immunology 2: 499-511. https://doi.org/10.1038/nri843

Peters, P.A. \& Warren, K.S. (1969). A rapid method of infecting mice and other laboratory animals with Schistosoma mansoni: subcutaneous injection. Journal of Parasitology 55: 558. https://doi.org/10.2307/3277297

Phan, A.D.T., Netzel, G., Chhim, P., Netzel, M.E. \& Sultanbawa, Y. (2019). Phytochemical characteristics and antimicrobial activity of australian grown garlic (Allium Sativum L.) cultivars. Foods 8: 358. https://doi.org/10.3390/foods 8090358

Riad, N.H.A., Taha, H.A. \& Mahmoud, Y.I. (2009). Effects of garlic on albino mice experimentally infected with Schistosoma mansoni: a parasitological and ultrastructural study. Tropical Biomedicine 26: 40-50.

Ricciardi, A., Zelt, N.H., Visitsunthorn, K., Dalton, J.P. \& Ndao, M. (2018). Immune mechanisms involved in schistosoma mansoni-Cathepsin $\mathrm{B}$ vaccine induced protection in mice. Frontiers In Immunology 9: 1710. https://doi.org/10.3389/ fimmu.2018.01710
Schmiedel, Y., Mombo-Ngoma, G., Labuda, L.A., Janse, J.J., de Gier, B., Adegnika, A.A., Issifou, S., Kremsner, P.G., Smits, H.H. \& Yazdanbakhsh, M. (2015). CD4+ CD25 hi FOXP3+ regulatory $T$ cells and cytokine responses in human schistosomiasis before and after treatment with praziquantel. PLoS Neglected Tropical Diseases 9: e0003995. https://doi.org/10.1371/journal.pntd.0003995

Shang, A., Cao, S.Y., Xu, X.Y., Gan, R.Y., Tang, G.Y., Corke, H., Mavumengwana, V. \& Li, H. (2019). Bioactive compounds and biological functions of garlic (Allium sativum L.). Foods 8: 246. https://doi.org/10.3390/foods 8070246

Shirgholami, Z., Borji, H., Mohebalian, H. \& Heidarpour, M. (2021). Effects of Allium sativum on IFN- $\gamma$ and IL4 concentrations in mice with cystic echinococcosis. Experimental Parasitology 220: 108042. https://doi.org/10.1016/ j.exppara.2020.108042

Szychowski, K.A., Rybczyńska-Tkaczyk, K., Gaweł-Bęben, K., Świeca, M., Karaś, M., Jakubczyk, A., Matysiak, M., Binduga, U.E. \& Gmiński, J. (2018). Characterization of active compounds of different garlic (Allium sativum L.) cultivars. Polish Journal of Food and Nutrition Sciences 68: 73-81. https://doi.org/10.1515/pjfns-2017-0005

Tang, C.L., Lei, J.H., Wang, T., Lu, S.J., Guan, F., Liu, W.Q. \& Li, Y.L. (2011). Effect of CD4 ${ }^{+}$CD25 $5^{+}$regulatory T cells on the immune evasion of Schistosoma japonicum. Parasitology Research 108: 477-480. https://doi.org/10.1007/s00436-0102089-2

Taylor, J.J., Mohrs, M. \& Pearce, E.J. (2006). Regulatory T cell responses develop in parallel to Th responses and control the magnitude and phenotype of the Th effector population. Journal of Immunology 176: 5839-5847. https:// doi.org/10.4049/jimmunol.176.10.5839

Taylor, M.D., van der Werf, N. \& Maizels, R.M. (2012) T cells in helminth infection: the regulators and the regulated. Trends in Immunology 33: 181-189. https://doi.org/10.1016/ j.it.2012.01.001

Turner, J.D., Jenkins, G.R., Hogg, K.G., Aynsley, S.A., Paveley, R.A., Cook, P.C., Coles, M.C. \& Mountford, A.P. (2011). CD4+ CD25+ regulatory cells contribute to the regulation of colonic Th2 granulomatous pathology caused by schistosome infection. PLoS Neglected Topical Diseases 5: e1269. https://doi.org/10.1371/journal.pntd.0001269

Watanabe, K., Mwinzi, P.N., Black, C.L., Muok, E.M., Karanja, D.M., Secor, W.E. \& Colley, D.G. (2007). T regulatory cell levels decrease in people infected with Schistosoma mansoni on effective treatment. The American Journal of Tropical Medicine and Hygiene 77: 676-682. 